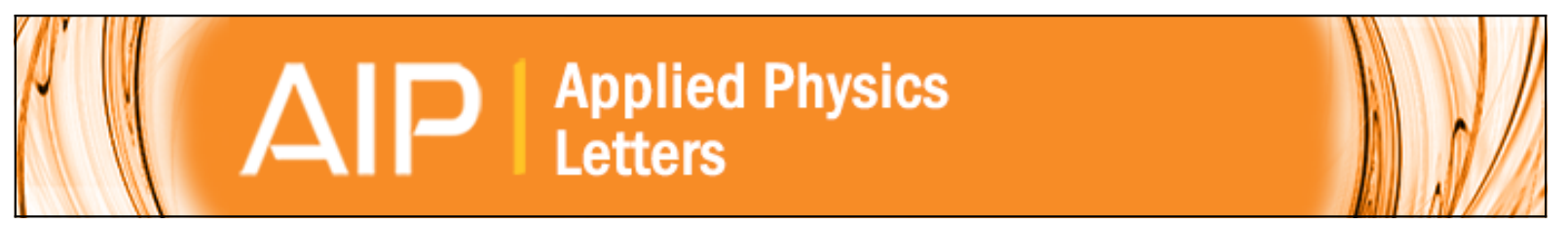

Electrocaloric enhancement near the morphotropic phase boundary in lead-free NBTKBT ceramics

Florian Le Goupil, James Bennett, Anna-Karin Axelsson, Matjaz Valant, Andrey Berenov, Andrew J. Bell, Tim P. Comyn, and Neil McN. Alford

Citation: Applied Physics Letters 107, 172903 (2015); doi: 10.1063/1.4934759

View online: http://dx.doi.org/10.1063/1.4934759

View Table of Contents: http://scitation.aip.org/content/aip/journal/apl/107/17?ver=pdfcov

Published by the AIP Publishing

Articles you may be interested in

Lead-free high-temperature dielectrics with wide operational range

J. Appl. Phys. 109, 034107 (2011); 10.1063/1.3544481

Morphotropic phase boundary and electrical properties of $\mathrm{K} 1-\mathrm{x} \mathrm{Na} \times \mathrm{NbO} 3$ lead-free ceramics

Appl. Phys. Lett. 94, 042905 (2009); 10.1063/1.3076105

Lead-free ceramics for pyroelectric applications

J. Appl. Phys. 103, 104105 (2008); 10.1063/1.2927252

Morphotropic phase boundary and piezoelectric properties of ( $\mathrm{Bi} 1 / 2 \mathrm{Na} 1 / 2) \mathrm{TiO} 3-(\mathrm{Bi} 1 / 2 \mathrm{~K} 1 / 2) \mathrm{Ti} O 3$ $-\mathrm{K} \mathrm{Nb} O 3$ lead-free piezoelectric ceramics

Appl. Phys. Lett. 91, 202908 (2007); 10.1063/1.2815918

Phase structure, microstructure, and electrical properties of bismuth modified potassium-sodium niobium leadfree ceramics

J. Appl. Phys. 102, 054102 (2007); 10.1063/1.2775997

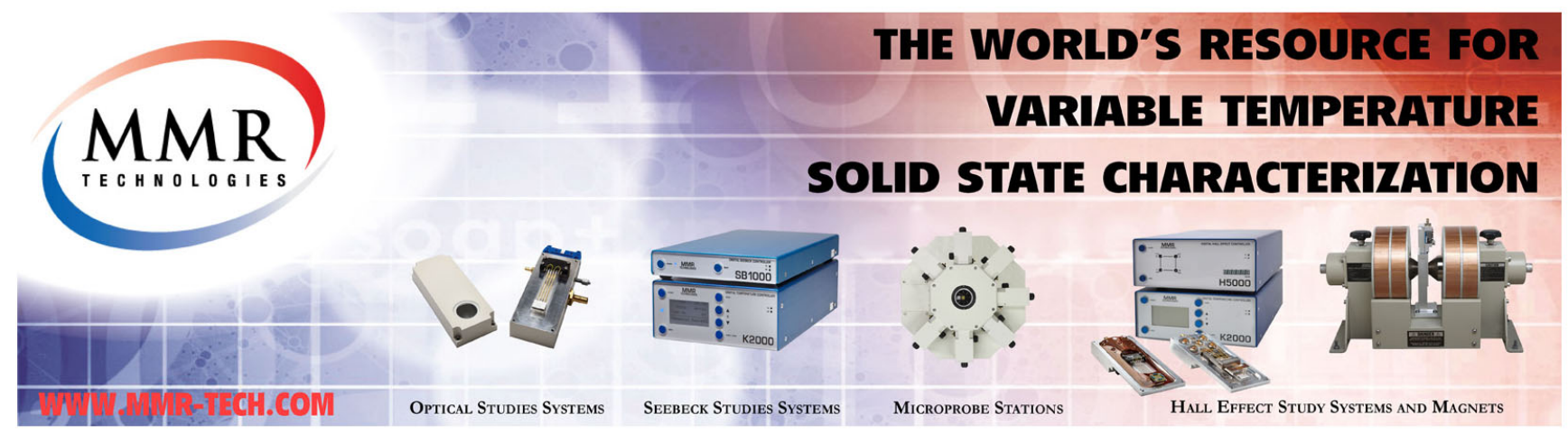




\title{
Electrocaloric enhancement near the morphotropic phase boundary in lead-free NBT-KBT ceramics
}

\author{
Florian Le Goupil, ${ }^{1, a)}$ James Bennett, ${ }^{2}$ Anna-Karin Axelsson, ${ }^{1,3}$ Matjaz Valant, ${ }^{4,5}$ \\ Andrey Berenov, ${ }^{1}$ Andrew J. Bell, ${ }^{2}$ Tim P. Comyn, ${ }^{2}$ and Neil McN. Alford ${ }^{1}$ \\ ${ }^{1}$ Department of Materials, Imperial College London, London SW7 2AZ, United Kingdom \\ ${ }^{2}$ Institute for Materials Research, School of Chemical and Process Engineering, University of Leeds, \\ Leeds LS2 9JT, United Kingdom \\ ${ }^{3}$ Department of Engineering Systems, London South Bank University, London SE1 OAA, United Kingdom \\ ${ }^{4}$ Institute of Fundamental and Frontier Sciences, University of Electronic Science and Technology of China, \\ Chengdu 610054, China \\ ${ }^{5}$ Materials Research Laboratory, University of Nova Gorica, Nova Gorica 5000, Slovenia
}

(Received 2 September 2015; accepted 16 October 2015; published online 27 October 2015)

\begin{abstract}
The electrocaloric effects (ECEs) of the morphotropic phase boundary (MPB) composition $0.82\left(\mathrm{Na}_{0.5} \mathrm{Bi}_{0.5}\right) \mathrm{TiO}_{3}-0.18\left(\mathrm{~K}_{0.5} \mathrm{Bi}_{0.5}\right) \mathrm{TiO}_{3}(\mathrm{NBT}-18 \mathrm{KBT})$ are studied by direct measurements. The maximum ECE $\Delta \mathrm{T}_{\max }=0.73 \mathrm{~K}$ is measured at $160^{\circ} \mathrm{C}$ under $22 \mathrm{kV} / \mathrm{cm}$. This corresponds to an ECE responsivity $(\Delta \mathrm{T} / \Delta \mathrm{E})$ of $0.33 \times 10^{-6} \mathrm{~K} \mathrm{~m} / \mathrm{V}$, which is comparable with the best reported values for lead-free ceramics. A comparison between the direct and indirect ECE measurements shows significant discrepancies. The direct measurement of both positive and negative electrocaloric effect confirms the presence of numerous polar phases near the MPB of NBT-based materials and highlights their potential for solid-state cooling based on high field-induced entropy changes. (C) 2015 AIP Publishing LLC. [http://dx.doi.org/10.1063/1.4934759]
\end{abstract}

The need for more efficient and environmental-friendly materials in the refrigeration industry has led to a significant effort towards the discovery of materials with potential for solid state cooling. Adiabatic depolarization cooling, which is based on the electrocaloric effect (ECE), has arisen as one of the main contender for solid state refrigeration techniques. In polar crystals, the net polarization increases with application of an external electric field. Under adiabatic conditions, the system compensates this alignment of dipoles with an increase in temperature, in order to keep the overall entropy of the system constant. This phenomenon is called the ECE. ${ }^{1}$ Several materials, both lead-containing, such as $\mathrm{Pb}\left(\mathrm{Zr}_{1-\mathrm{x}} \mathrm{Ti}_{\mathrm{x}}\right) \mathrm{O}_{3} \quad(\mathrm{PZT}){ }^{2}{ }^{2}(1-\mathrm{x}) \mathrm{Pb}\left(\mathrm{Zn}_{1 / 3} \mathrm{Nb}_{2 / 3}\right) \mathrm{O}_{3}-\mathrm{xPTiO}_{3}$ $(\mathrm{PZN}-\mathrm{PT}){ }^{3}$ or $(1-\mathrm{x}) \mathrm{Pb}\left(\mathrm{Mg}_{1 / 3} \mathrm{Nb}_{2 / 3}\right) \mathrm{O}_{3}-\mathrm{xPbTiO}_{3} \quad(\mathrm{PMN}-$ xPT) ${ }^{4,5}$ and lead-free, such as $\mathrm{BaTiO}_{3}(\mathrm{BT}),{ }^{6} \mathrm{Sr}_{\mathrm{x}} \mathrm{Ba}_{(1-\mathrm{x})} \mathrm{Nb}_{2} \mathrm{O}_{3}$ $(\mathrm{SBN}),{ }^{7,8}$ or $\left(\mathrm{Na}_{0.5} \mathrm{Bi}_{0.5}\right) \mathrm{TiO}_{3}(\mathrm{NBT}),{ }^{9}$ have been considered for electrocaloric cooling. Lead-free relaxor ferroelectrics (FEs) with high dielectric strength ${ }^{10}$ seem highly suitable candidates; however, it is critical to find ways to increase their ECE.

One way forward is to operate in regions of the phase diagram close to critical points $(\mathrm{CPs})$, where the energy barriers for switching between different FE phases are significantly reduced. As more than one polar phase coexist near the $\mathrm{CP}$, the entropy of the unpoled system is greatly increased, which leads to an ECE enhancement. ${ }^{11}$ Such an ECE enhancement was reported recently by Qian et al. in $\mathrm{Zr}$ doped BT near the CP. ${ }^{12}$ Furthermore, it has been shown that an invariant critical point, where the number of available polar phases in the composition-temperature-electric field phase diagram is maximised, can be found in materials with a morphotropic phase boundary (MPB). Some of the highest ECE

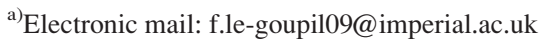

performances ever reported were found in the $\mathrm{Pb}$-containing compounds close to their MPB, such as PMN-30PT. ${ }^{4}$ The ECE of some lead-free materials with compositions near the $\mathrm{CP}$, such as $\mathrm{Zr}$-doped $\mathrm{Ba}_{0.8} \mathrm{Ca}_{0.2} \mathrm{TiO}_{3},{ }^{13}$ Sn-doped $\mathrm{BT},{ }^{14}$ or Sr-doped NBT-BT, ${ }^{15,16}$ has also been reported, but very few were studied by direct ECE measurements.

NBT forms solid solutions with numerous FE compounds, such as $\mathrm{BT}, \mathrm{KNbO}_{3}(\mathrm{KN})$, or $\left(\mathrm{K}_{0.5} \mathrm{Bi}_{0.5}\right) \mathrm{TiO}_{3}$ (KBT), and several MPB have been reported. ${ }^{17,18}$ Most thermal and electromechanical properties of these materials have been found to be significantly increased in the vicinity of the MPB. The NBT-KBT phase diagram shows a MPB near $18 \%$-KBT, where the rhombohedral, tetragonal, and cubic phase can exist. ${ }^{19}$ NBT-KBT shows its highest reported electromechanical properties, including polarization and piezoelectric coefficient near this composition. ${ }^{19}$ NBT-18KBT has been considered for electrocaloric cooling and its ECE has been reported; ${ }^{20}$ however, only indirect evaluations of the ECE have been published and actual ECE values remain to be confirmed by direct measurements.

Here, we report direct measurements of the ECE enhancement in NBT-based bulk ceramics near the MPB.

NBT-18KBT ceramic powders were prepared by conventional solid-state synthesis. Stoichiometric quantities of the starting reagents, $\mathrm{Bi}_{2} \mathrm{O}_{3}, \mathrm{~K}_{2} \mathrm{CO}_{3}, \mathrm{Na}_{2} \mathrm{CO}_{3}$, and $\mathrm{TiO}_{2}$ (99.99\% purity, Sigma-Aldrich), were mixed in a planetary mill for $24 \mathrm{~h}$ with the slip then dried. The powder was calcined in covered crucibles at $850^{\circ} \mathrm{C}$ for $4 \mathrm{~h}$, then sieved through a $300 \mu \mathrm{m}$ mesh. The calcined powder was subjected to high energy attrition milling (Willy A. Bachofen, Basel, Switzerland) to reduce the particle size for $2 \mathrm{~h}$ with stabilized yttria stabilized zirconia balls in iso-propyl alcohol. $2 \mathrm{wt}$ \% binder (Glascol HA-40) was added before drying and sieving. The calcined powder was pressed into pellets and 

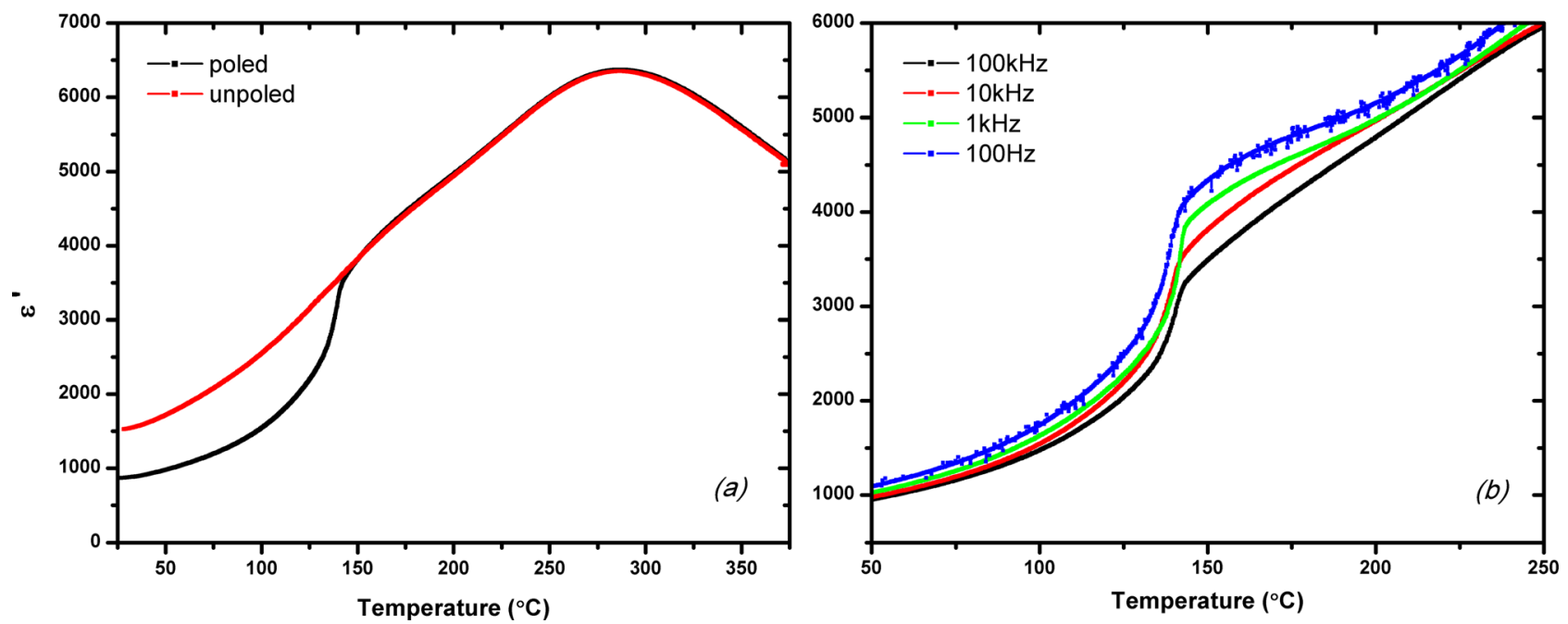

FIG. 1. Real part of the dielectric permittivity versus temperature measured for NBT-18KBT (a) on poled and unpoled ceramics measured at $10 \mathrm{kHz}$ upon heating and (b) as a function of frequency near Td for the poled ceramics.

sintered at $1150{ }^{\circ} \mathrm{C}$ for $2 \mathrm{~h}$ with a density of $5.752 \mathrm{~g} / \mathrm{cm}^{3}$ realised. The dielectric permittivity was measured with a HP 4263B LCR meter from $25^{\circ} \mathrm{C}$ to $400^{\circ} \mathrm{C}$ at different frequencies (from $100 \mathrm{~Hz}$ to $100 \mathrm{kHz}$ ) on both poled and unpoled ceramics. The samples were poled under high electric field $(22 \mathrm{kV} / \mathrm{cm})$ at $100^{\circ} \mathrm{C}$. The polarization versus electric field measurements $(P-E)$, along with leakage current measurements, were carried out using a Radiant LC Precision Unit with a High Voltage Amplifier (TREK model 609B) from $40^{\circ} \mathrm{C}$ to $165^{\circ} \mathrm{C}$. The specific heat capacity of NBT-18KBT was measured experimentally and was found to linearly increase over the studied temperature range from 510 to $557 \mathrm{~J} \mathrm{~kg}^{-1} \mathrm{~K}^{-1}$. The direct ECE measurements were performed on the unpoled ceramics with a modified-Differential Scanning Calorimeter (DSC) (Netzsch DSC 200 F3), as described elsewhere. ${ }^{4}$

Fig. 1(a) shows the real part of the dielectric permittivity as a function of temperature measured for NBT-18KBT for poled and unpoled ceramics at $10 \mathrm{kHz}$ upon heating. The shape of the plot for the poled sample is typical of the NBTbased system, with two successive dielectric anomalies, one $\sim 150^{\circ} \mathrm{C}$ and one $\sim 287^{\circ} \mathrm{C}$. Although there is still debate on the nature of the phases found in this material system, these anomalies are believed to be the convolution of three distinct processes: The dielectric relaxation due to a mixture of polar nano-regions (PNRs) with two different local symmetry, the diffuse phase transition of lower symmetry PNRs into higher symmetry PNRs, and the additional dielectric relaxation of existing PNRs. ${ }^{21}$ The anomaly observed at lower temperatures $\left(\sim 150^{\circ} \mathrm{C}\right)$ corresponds to the temperature of depolarisation (Td), which marks the transition from the long-range FE regions to the short-range PNRs. The maximum ECE is expected to be found near this lower temperature in conventional ferroelectrics, but it is shifted to much higher temperatures when high fields are applied to the relaxors due to the contribution of the PNRs. The values of both the temperature of maximum permittivity $(\mathrm{Tm})$ and $\mathrm{Td}$ observed in this permittivity measurement are in good agreement with values reported by Hiruma et al. for the same composition. ${ }^{19}$ The significant frequency dispersion observed near $\mathrm{Td}$ for the poled ceramics, in Fig. 1(b), confirms the presence of a weakly polar relaxor phase with short range PNRs.

Fig. 2 shows the polarization versus applied electric field measured for the NBT-18KBT unpoled ceramics between $130^{\circ} \mathrm{C}$ and $165^{\circ} \mathrm{C}$. Only the upper branch of the positive side of the bipolar loop is plotted for clarity purposes. It can be seen that large polarisation values (over $25 \mu \mathrm{C} / \mathrm{cm}^{2}$ ) are obtained at $22 \mathrm{kV} / \mathrm{cm}$. The inset of Fig. 2 shows the evolution of the remanent polarization as a function of temperature. $\mathrm{Td}$, defined as the temperature of the steepest decrease of the remanent polarization, was found to be $\sim 150{ }^{\circ} \mathrm{C}$, which is in good agreement with the values obtained from the dielectric permittivity measurements.

Fig. 3 shows the ECE versus temperature measured for the NBT-18KBT unpoled ceramics for different values of applied electric field. The ECE steadily increases with temperature until it reaches $\mathrm{Td}$, where a sharp increase is observed. A strong field-dependence of the absolute value and the temperature of the maximum $\operatorname{ECE}\left(\Delta \mathrm{T}_{\max }\right)$ is observed, as expected from the relaxor ferroelectrics. The

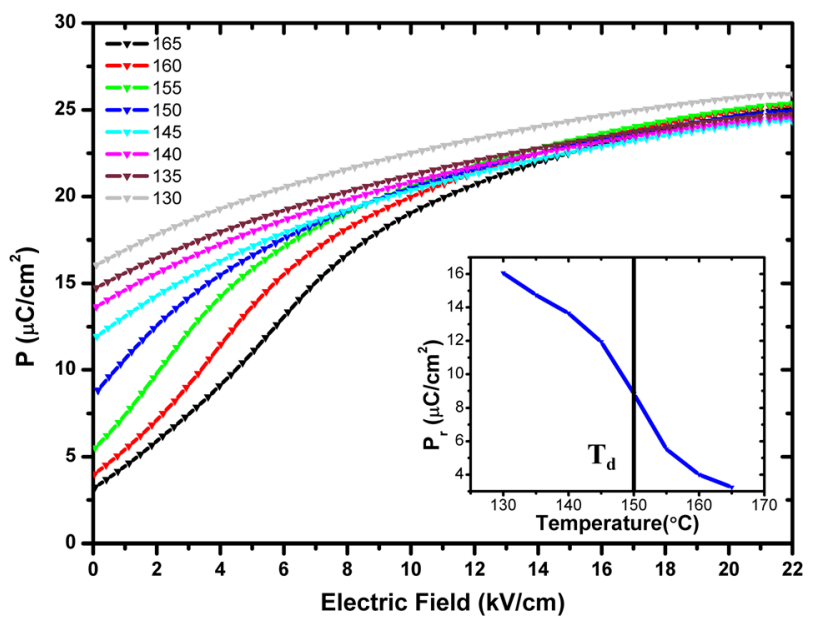

FIG. 2. Polarisation versus applied electric field measured for the NBT18KBT unpoled ceramics between $130^{\circ} \mathrm{C}$ and $165^{\circ} \mathrm{C}$, the inset shows the position of $\mathrm{Td}$ determined from the temperature dependence of the remanent polarisation. 


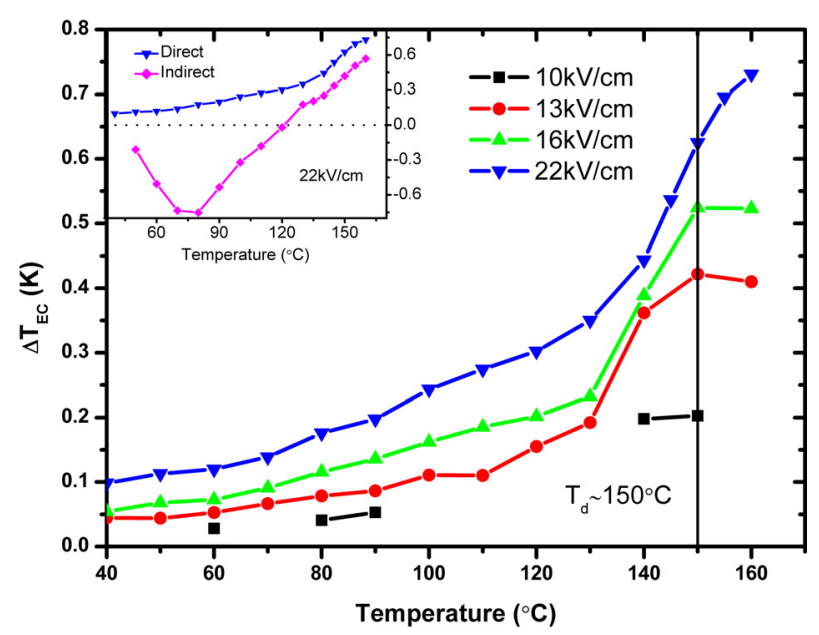

FIG. 3. ECE versus temperature measured for the NBT-18KBT unpoled ceramics for different values of applied electric field. The vertical line marks the position of $\mathrm{Td}$. The inset shows a comparison between the direct and indirect ECE versus temperature measured for $22 \mathrm{kV} / \mathrm{cm}$.

maximum ECE, $\Delta \mathrm{T}_{\max }=0.73 \mathrm{~K}$, was observed at $160^{\circ} \mathrm{C}$ under $22 \mathrm{kV} / \mathrm{cm}$. Above $13 \mathrm{kV} / \mathrm{cm}$, the ECE increases linearly over the studied range of applied field, with a slope of $0.33 \times 10^{-6} \mathrm{~K} \mathrm{~m} / \mathrm{V}$. This slope, which is referred to as the ECE responsivity, is often used to compare the performances of ECE materials in the literature. The ECE responsivity must be used with caution as it is unclear if the linear evolution can still be found at much higher field values and the dielectric strength of the ceramic will limit the electric field application. The best ECE responsivities reported for leadfree materials are found between 0.31 and $0.34 \times 10^{-6} \mathrm{~K} \mathrm{~m} /$ $\mathrm{V}$ (Refs. 12 and 13) and are comparable to what we obtained for NBT-18KBT. These results highlight how promising NBT-based material with MPB are for electrocaloric cooling applications. The only current issue is the fact that most of reported MPB compositions have their $\mathrm{Td}$ too high $\left(>100^{\circ} \mathrm{C}\right)$ for practical applications, and more systems need to be studied to shift it closer to the room temperature. Hiruma et ll $^{22}$ reported that, similar to lead-based perovskites, the position of the MPB in $(1-\mathrm{x}) \mathrm{NBT}-\mathrm{xABO}_{3}$ materials depends on the tolerance factor of the end-member perovskite. The use of the formula that they proposed could be an effective tool to efficiently screen different types of both A- and B-sites dopants, which could lead to a near-RT MPB.

The inset of Fig. 3 shows a comparison between the direct and indirect measurements obtained for $22 \mathrm{kV} / \mathrm{cm}$. The method used to calculate the indirect measurement is given elsewhere. ${ }^{4}$ There is a good agreement between both sets of data at high temperature with an increasing trend observed between $130{ }^{\circ} \mathrm{C}$ and $160^{\circ} \mathrm{C}$ and the maximum indirect ECE also measured at $160^{\circ} \mathrm{C}$. However, the absolute value $\Delta \mathrm{T}_{\max }=0.57 \mathrm{~K}$, which corresponds to an ECE responsivity of only $0.26 \times 10^{-6} \mathrm{~K} \mathrm{~m} / \mathrm{V}$, is significantly lower than that observed by direct measurements. Furthermore, it can be seen that there are significant discrepancies at lower temperatures. A positive ECE is observed by direct measurements with small values of ECE slowly increasing with temperature. However, the indirect measurements show a large negative ECE with a maximum of $\left|\Delta \mathrm{T}_{\mathrm{EC}}\right|$ observed near $80^{\circ} \mathrm{C}$.
The indirect ECE only becomes positive near $120^{\circ} \mathrm{C}$. The negative ECE observed by indirect measurements is a result of the combination of the hysteresis loops not being fully saturated at $22 \mathrm{kV} / \mathrm{cm}$ and the decrease of the coercive field with increasing temperature, which leads to an increase of the induced polarisation with temperature. As the pyroelectric coefficient is used for the indirect measurement, a positive $\mathrm{dP} / \mathrm{dT}$ results in a negative effect. Our direct measurements clearly show that the ECE is positive in that range of temperature, which highlights that the indirect methods, based on Maxwell's equations, are not valid in the nonequilibrium conditions that accompanies unsaturated ceramics. $^{23}$ Only when fully saturated hysteresis loops are observed (above $130{ }^{\circ} \mathrm{C}$ ), the trend of the indirect ECE starts to match that obtained by direct measurements. Indirect ECE measurements performed on NBT-18KBT were reported by Cao et $a .^{20}$ Although they applied electric fields high enough to saturate the ceramics and observed a positive ECE over the studied range of temperature, they found a maximum ECE of $1.06 \mathrm{~K}$ at $80^{\circ} \mathrm{C}$ under $50 \mathrm{kV} / \mathrm{cm}$, which correspond to an ECE responsivity of only $0.22 \times 10^{-6} \mathrm{~K} \mathrm{~m} / \mathrm{V}$ and is much lower than what we measured directly. The significant discrepancies between the direct and indirect measurements highlights the limitations of indirect ECE measurements and emphasises the need for a systematic direct characterisation of the ECE properties, especially for complex relaxor ferroelectric systems, as previously reported by Lu et al. ${ }^{24}$

Fig. 4 shows the ECE versus applied electric field measured for NBT-18KBT at $60^{\circ} \mathrm{C}$. It can be seen that the ECE increases almost linearly with electric field above $7 \mathrm{kV} / \mathrm{cm}$, with a regular ECE response on the DSC measurement, as shown in the inset of the bottom right corner. However, Fig. 4 also shows that a negative ECE is observed at lower fields, around $5 \mathrm{kV} / \mathrm{cm}$. It can be seen in the inset in the top left corner that there is a reversal of the observed peaks, with an endothermic peak observed upon application of the field and an exothermic observed upon removal, as seen in $\langle 001\rangle$ PMN-30PT single crystals. ${ }^{4,25}$ A negative ECE has also been observed by indirect ECE measurements on $\mathrm{NBT},{ }^{9}$ where it

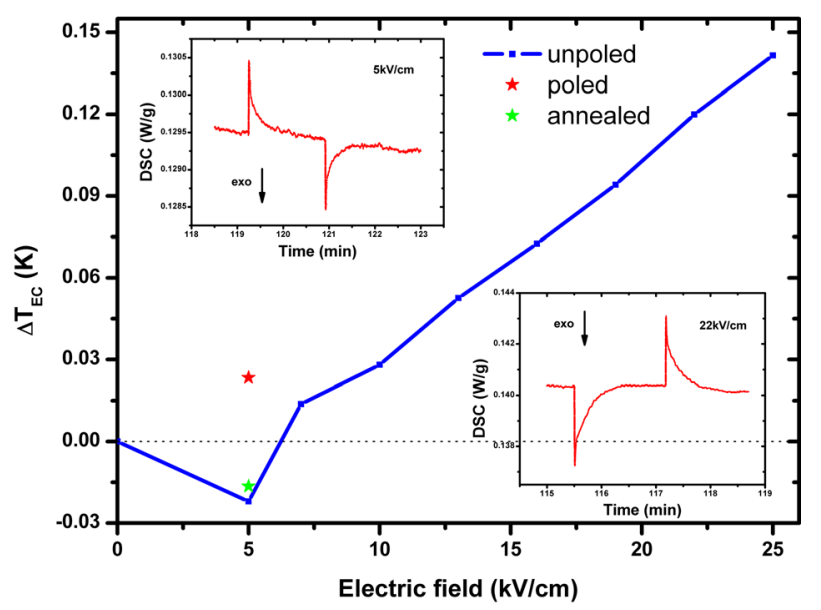

FIG. 4. ECE versus applied electric field measured for the NBT-18KBT unpoled ceramics at $60^{\circ} \mathrm{C}$. The data measured at $5 \mathrm{kV} / \mathrm{cm}$ on poled and annealed ceramics are also presented. The insets show the DSC response for $5 \mathrm{kV} / \mathrm{cm}$ (left) and $22 \mathrm{kV} / \mathrm{cm}$ (right); the peaks going down are exothermic. 
was attributed to the presence of a field-induced phase transition from tetragonal AFE to a more entropic tetragonal FE phase. The negative effect in NBT-18KBT is most likely also due to the presence of a weakly polar phase with different dipolar directions at low applied fields as reported by Viola et al. $^{26}$ Similar to NBT-BT, ${ }^{27,28}$ unpoled ceramics with compositions near the MPB of NBT-KBT show a mixture of $R 3 \mathrm{c}$ and $P 4 \mathrm{bm}$ polar nano-regions. ${ }^{29}$ The tetragonal $P 4 \mathrm{bm}$ phase is a weakly polar relaxor ferrielectric with antiparallel cation displacements along the polar axis. ${ }^{27,30}$ The application of an electric field higher than the coercive field induces the formation of a long-range order FE phase, with the $R 3 \mathrm{c}$ or $P 4 \mathrm{~mm}$ structure depending on the composition. However, when a smaller electric is applied, the $P 4 \mathrm{bm}$ nanodomains coalesce into thin lamellar domains while maintaining the P4bm structure, as observed by Guo et al. with in situ TEM. ${ }^{31}$ The formation of this lamellar domains with antiparallel dipolar directions is responsible for the negative ECE observed at $5 \mathrm{kV} / \mathrm{cm}$ on the unpoled ceramics. The application of low electric fields to this phase actually increases the dipolar disorder of the system due to the different dipolar directions available, which leads to a fieldinduced entropy increase and a negative ECE. The observation of a negative ECE in that case is consistent with reports from Ponomareva and Lisenkov ${ }^{32}$ and Axelsson et al., ${ }^{25}$ who attributed its occurrence to the non-collinearity between the direction of field application and the dipolar directions available in the sample. The application of a stronger field induces the irreversible formation of the FE phase, which is accompanied by the conventional field-induced entropy reduction and a positive ECE, as observed for electric fields above $7 \mathrm{kV} / \mathrm{cm}$. Similarly, when a $5 \mathrm{kV} / \mathrm{cm}$-electric field is applied to a poled ceramic, a positive ECE is observed as the FE phase induced by the poling did not revert back to the weakly polar phase after the field was removed. However, if the poled ceramic is depoled by annealing at temperatures above Td, only the weakly polar phase is present upon cooling and a negative ECE is produced by the application of a $5 \mathrm{kV} / \mathrm{cm}$-electric field, which was also confirmed by our measurements, as shown in Fig. 4. The presence of the negative ECE highlights the numerous polar phases available in the NBT-based ceramics and is another proof of their high potential for solid-state cooling based on high field-induced entropy changes.

In conclusion, we have reported the direct measurements of the ECE enhancement resulting from the MPB formed by the solid solution of NBT with KBT. A maximum ECE $\Delta \mathrm{T}_{\max }=0.73 \mathrm{~K}$ was measured at $160^{\circ} \mathrm{C}$ under $22 \mathrm{kV} / \mathrm{cm}$ for NBT-18KBT. This corresponds to an ECE responsivity $(\Delta \mathrm{T} /$ $\Delta \mathrm{E})$ of $0.33 \times 10^{-6} \mathrm{~K} \mathrm{~m} / \mathrm{V}$, which is comparable with the best reported values for lead-free ceramics. The significant discrepancies between the direct and indirect measurements have also emphasised the need for a systematic direct characterisation of the ECE properties, especially for complex relaxor ferroelectric systems. The direct measurement of both positive and negative electrocaloric effect also confirmed the presence of numerous polar phases near the MPB of NBT-based materials and highlighted their potential for solid-state cooling based on high field-induced entropy changes.

This project was funded by EPSRC (No. EP/G060940/1).

${ }^{1}$ M. Valant, Prog. Mater. Sci. 57, 980 (2012).

${ }^{2}$ A. S. Mischenko, Q. Zhang, J. F. Scott, R. W. Whatmore, and N. D. Mathur, Science 311, 1270 (2006).

${ }^{3}$ M. Valant, L. Dunne, A.-K. Axelsson, N. Alford, G. Manos, J. Peräntie, J. Hagberg, H. Jantunen, and A. Dabkowski, Phys. Rev. B 81, 214110 (2010).

${ }^{4}$ F. Le Goupil, A. Berenov, A.-K. Axelsson, M. Valant, and N. M. Alford, J. Appl. Phys. 111, 124109 (2012).

${ }^{5}$ J. Perantie, J. Hagberg, A. Uusimaki, and H. Jantunen, Phys. Rev. B 82, 134119 (2010).

${ }^{6}$ X. Moya, E. Stern-Taulats, S. Crossley, D. González-Alonso, S. KarNarayan, A. Planes, L. Mañosa, and N. D. Mathur, Adv. Mater. 25, 1360 (2013).

${ }^{7}$ F. Le Goupil, A.-K. Axelsson, L. J. Dunne, M. Valant, G. Manos, T. Lukasiewicz, J. Dec, A. Berenov, and N. M. Alford, Adv. Energy Mater. 4, 1301688 (2014).

${ }^{8}$ F. Le Goupil, A.-K. Axelsson, M. Valant, T. Lukasiewicz, J. Dec, A. Berenov, and N. M. Alford, Appl. Phys. Lett. 104, 222911 (2014).

${ }^{9}$ Y. Bai, G. P. Zheng, and S. Q. Shi, Mater. Res. Bull. 46, 1866 (2011).

${ }^{10}$ M. Valant, A.-K. Axelsson, F. Le Goupil, and N. M. Alford, Mater. Chem. Phys. 136, 277 (2012).

${ }^{11}$ Z. K. Liu, X. Li, and Q. M. Zhang, Appl. Phys. Lett. 101, 082904 (2012).

${ }^{12}$ X.-S. Qian, H.-J. Ye, Y.-T. Zhang, H. Gu, X. Li, C. A. Randall, and Q. M. Zhang, Adv. Funct. Mater. 24, 1300 (2014).

${ }^{13}$ B. Asbani, J.-L. Dellis, A. Lahmar, M. Courty, M. Amjoud, Y. Gagou, K. Djellab, D. Mezzane, Z. Kutnjak, and M. El Marssi, Appl. Phys. Lett. 106, 042902 (2015).

${ }^{14}$ S. K. Upadhyay, V. R. Reddy, P. Bag, R. Rawat, S. M. Gupta, and A. Gupta, Appl. Phys. Lett. 105, 112907 (2014).

${ }^{15}$ S. Uddin, G.-P. Zheng, Y. Iqbal, R. Ubic, and J. Yang, J. Appl. Phys. 114, 213519 (2013).

${ }^{16}$ J. Tang, F. Wang, X. Zhao, H. Luo, L. Luo, and W. Shi, Ceram. Int. 41, 5888 (2015).

${ }^{17}$ Y. Hiruma, H. Nagata, and T. Takenaka, J. Appl. Phys. 104, 124106 (2008).

${ }^{18}$ S.-T. Zhang, A. B. Kounga, W. Jo, C. Jamin, K. Seifert, T. Granzow, J. Rödel, and D. Damjanovic, Adv. Mater. 21, 4716 (2009).

${ }^{19}$ Y. Hiruma, K. Yoshii, H. Nagata, and T. Takenaka, J. Appl. Phys. 103, 084121 (2008).

${ }^{20}$ W. P. Cao, W. L. Li, D. Xu, Y. F. Hou, W. Wang, and W. D. Fei, Ceram. Int. 40, 9273 (2014).

${ }^{21}$ W. Jo, R. Dittmer, M. Acosta, J. Zang, C. Groh, E. Sapper, K. Wang, and J. Rödel, J. Electroceram. 29, 71 (2012).

${ }^{22}$ Y. Hiruma, H. Nagata, and T. Takenaka, Jpn. J. Appl. Phys., Part 148 , 09KC08 (2009).

${ }^{23}$ L. J. Dunne, M. Valant, G. Manos, A.-K. Axelsson, and N. M. Alford, Appl. Phys. Lett. 93, 122906 (2008).

${ }^{24}$ S. G. Lu, B. Rozic, Q. M. Zhang, Z. Kutnjak, R. Pirc, M. R. Lin, X. Y. Li, and L. Gorny, Appl. Phys. Lett. 97, 202901 (2010).

${ }^{25}$ A.-K. Axelsson, F. Le Goupil, L. J. Dunne, G. Manos, M. Valant, and N. M. Alford, Appl. Phys. Lett. 102, 102902 (2013).

${ }^{26}$ G. Viola, R. McKinnon, V. Koval, A. Adomkevicius, S. Dunn, and H. Yan, J. Phys. Chem. C 118, 8564 (2014).

${ }^{27}$ X. Tan, C. Ma, J. Frederick, S. Beckman, and K. G. Webber, J. Am. Ceram. Soc. 94, 4091 (2011).

${ }^{28}$ C. Ma, H. Guo, S. P. Beckman, and X. Tan, Phys. Rev. Lett. 109, 107602 (2012).

${ }^{29}$ H. Zhang, C. Chen, X. Zhao, H. Deng, B. Ren, X. Li, H. Luo, and S. Li, Solid State Commun. 201, 125 (2015).

${ }^{30}$ G. O. Jones and P. A. Thomas, Acta Crystallogr., Sect. B: Struct. Sci. 56, 426 (2000).

${ }^{31}$ H. Guo, C. Ma, X. Liu, and X. Tan, Appl. Phys. Lett. 102, 092902 (2013).

${ }^{32}$ I. Ponomareva and S. Lisenkov, Phys. Rev. Lett. 108, 167604 (2012). 